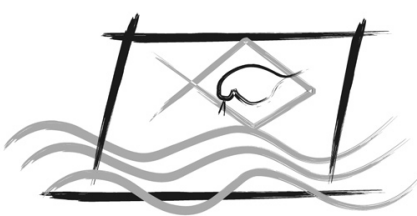

ECOTOX - BRASIL

\title{
Population Approach in Ecotoxicology (Stress Ecology)
}

\author{
M.N. FLYNN ${ }^{1} \&$ W.R.L.S. PEREIRA ${ }^{2}$ \\ ${ }^{1}$ FT, Campinas - Unicamp, 13083-852, Campinas/SP. \\ ${ }^{2}$ Bio.Sensu Consultoria Ecológica, 04419-030, São Paulo.
}

(Received January 20, 2012; Accept March 15, 2013)

\begin{abstract}
Several lines of evidence suggest that the effects of stressors on populations can be calculated accurately by population modeling. Using monitoring data of natural population, population models were applied and the possibility of establishing environmental diagnoses from strictly ecological concepts is discussed. A procedure is offered for the modeling of natural population data and the establishment of population endpoints.
\end{abstract}

Key words: Ecotoxicology. Population Models. Hurst Exponent. Time series analysis.

Abordagem populacional em ecotoxicologia (Ecologia do estresse)

\section{Resumo}

Diversas linhas de evidências sugerem que os efeitos de estressores atuando em populações podem ser calculados acuradamente pela modelagem populacional. Usando dados de monitoramento de populações naturais, modelos populacionais foram aplicados e a possibilidade de estabelecer diagnoses ambientais a partir de conceitos estritamente ecológicos é discutida. Um procedimento é oferecido para a modelagem de dados de populações naturais e o estabelecimento de endpoints populacionais.

Palavras-chave: Ecotoxicology. Modelos populacionais. Expoente de Hurst. Análise de séries temporais.

\section{INTRODUCTION}

The term ecotoxicology was coined in 1969 by Rene Truhaut to name the branch of toxicology concerned with "toxic effects, caused by natural or synthetic pollutants, to the constituents of ecosystems, animal (including human), vegetable and microbial, in an integral context". As a branch of toxicology methodological characteristics such as focus on standardization, laboratory tests with standard species and risk assessment were used. This approach did not stimulate the incorporation of ecological theory. The current need to assess toxicants effects on natural populations and ecological systems has motivated the appearance of a number of predictive models.
Which guidelines can be derived from ecological theory to support toxic effects assessment in natural populations and ecosystems? Which general laws ecology has to offer in order to support a robust risk assessment? It is usually presumed that ecology does not have the predictive power of physics or chemistry. The establishment of causal connections is a relatively simple and direct procedure in these sciences as well as in the most reductionist derivations of ecotoxicology, where causal relationships are established conclusively (or so it seems). In population and in systemic approaches multiple causalities are relatively common and a hypothesis can rarely be considered as definitely refuted or refutable. Perhaps this is why ecology has not yet developed unifying, consensual and lasting principles or concepts.

*Corresponding author: Máurea Nicolette Flynn, e-mail: maureaflynn@gmail.com 
Many ecological phenomena are constrained by the organisms involved and their ecological environment. Most ecological experiments are only valid for the time, place and conditions under which they occur. However, these restrictions and experimental non-reproducibility are not a fact expected for all ecological fields. In population ecology there are many general principles, with replicable standards and rules applicable to a wide range of topics focusing mainly on: epidemiology of diseases related to chemical agents, population genetics, effects on general qualities such as population demographics and persistence rates.

The classical concerned of ecotoxicology with experimental tests, dose-effectanalysisandestimationofeffectconcentrations have provided a solid basis for environmental regulation based on maximum acceptable chemical concentrations. In regions of Europe and North America most pollutants are regulated and consequently, their concentrations are declining. Van Straalen (2003) discussed reasons why major innovations are not to be expected in classical ecotoxicology and argues that ecotoxicology cries out to be more "eco". He points out branches of ecology, such as age structures modeling, community theory, molecular analysis, life strategies theories, food webs characterization and spatial analysis that can fully contribute to ecotoxicology: and suggests the term "ecology of stress" as a more appropriate reference to the integration between ecology and ecotoxicology.

The ecology of stress expands the spectrum activity of classical ecotoxicology, encompassing the predictive power (at least a priori) of population dynamics. As noticed by Turchin (2001) three population dynamics principles are similar to physics general laws: the exponential growth (Malthus equation), self-limiting population (Verhust-Pearl logistic growth model), and consumer-resource oscillation (LotkaVolterra classical predator-prey system). The incorporation of such "laws" or "rules" expands toxicological interpretation to natural systems.

This paper examines the application of widely accepted population principles in predicting the behavior from existing monitoring data of natural populations.

\section{DEVELOPMENT}

In this part it will be presented theoretical population dynamics principles in development since Malthus (1798) and statistical physics knowledge that were incorporated to ecology more recently. It is divided in two sections, the first one dealing with the historical development of population dynamics theory (exponential growth, population selflimitation and consumer-resource system) and the second one with the detection of population patterns in an ecological system.

Population exponential growth, self-limitation and consumer-resource system. The earliest source of modern population ecology is theoretical and analytical derived from the seventeenth century demography, developed as an attempt to understand and control epidemics, especially the plague in England. The London population then doubled every 64 years, estimative based on births, deaths and number of marriages primary statistics. The population growth would implicitly entail a deterioration of life quality, unless followed by an increase in resources. This pessimistic view was explored by Malthus, who noted that populations tend to grow exponentially while their resources arithmetically (see Fig. 1 and 3), leading to the natural conclusion that population growth tends to be controlled by hunger and misery. Below, the equation and solution proposed by Malthus to describe such behavior:

$$
\frac{d N}{d t}=r N=(b-d) N N(t)=N(0) e^{r t}=N(0) e^{(b-d) t}
$$

The equation differential form indicates that the rate of population growth $N$ as a function of time $\left(\frac{d N}{d t}\right)$ is equal to population growth rate $(r)$ multiplied by number of inhabitants $(N)$. The rate of population growth is translated into a balance between rate of born individuals $(b)$ and rate of dead individuals $(d)$ and regulates population growth.Initial population size is represented by $N(0)$. An ecological condition $N(0)=2$ is essential, i.e., a breeding pair at least (except in species such as bacteria with different forms of reproduction). Although the model is accepted by environmentalists it rarely represents a real population temporal behavior.

In the following century, the demographic conceptions found full expression in mathematical modeling. The most famous of these models was proposed by the Belgian Verhulst (1845) launching the hypothesis that human population growth is better represented by the logistic curve (see Fig. 1). This curve, rediscovered by Pearl (1925), was applied also to animal populations. This model represented an improvement of Malthus theory by the insertion of the ratio, $\frac{(K-N)}{K}$, a term that regulates growth rate $(r)$ :

$$
\frac{d N}{d t}=r\left(\frac{K-N}{K}\right) N=r\left(1-\frac{N}{K}\right) N N(t)=\frac{N(0) e^{r t}}{\left[1+\frac{N(0)\left(e^{r t}-1\right)}{K}\right]}
$$

Populations would reach an equilibrium state, so called selfsustaining capacity. Therefore, there would be a persistent maximum size for the surviving population expressed by $K$ value, introducing a new concept to be incorporated into ecology, carrying capacity.

The sigmoid curve, unlike the exponential, admits a moment when the population growth relative rate breaks ( $\left.\frac{d N}{d t}=n N(K-N) K=0\right)$. The population at this point is under the effect of an environmental imposed growth constrain. The maximum effect of this restriction is represented when the population reaches carrying capacity, with densities around $K$ . The population then is in equilibrium, a stable state. Unstable balance, although rare, may occur both in nature and in theory as described by May, (1976a) and Hassell et al. (1976).

It is possible to speculate that a number of known species persistent in their habitats probably have sustained several natural disasters (and still struggle against human interference), and that different evolutionary processes have occurred to 
keep them in balance. Does such condition exist in nature? Yes, and it can be seen in the following adapted curves from documented data (Fig. 1).

Sigmoidal growth was described in sheep (Ovies aries) population in Australia (Davidson, 1938a) and Tasmania (Davidson, 1938b) (Fig. 1a and 1b, respectively). This pattern could be seen again in fisher (Martes pennanti) data (Novak et al., 1987) where the sigmoid curve fitted well to data, disclosing an early exponential growth (Fig. 1c). The whooping crane (Grus americana), a protected bird (Canadian Wildlife Service and U.S. Fish and Wildlife Service, 2005) reveals an exponential growth and different carrying-capacity values (Fig. 1d). African Penguin (Spheniscus demersus) populations were monitored in 13 geographical points in South Africa and three distinct regions, Robben Island, Boulders Island and Stone Point (Fig. 1e), showing exponential growth (Underhill
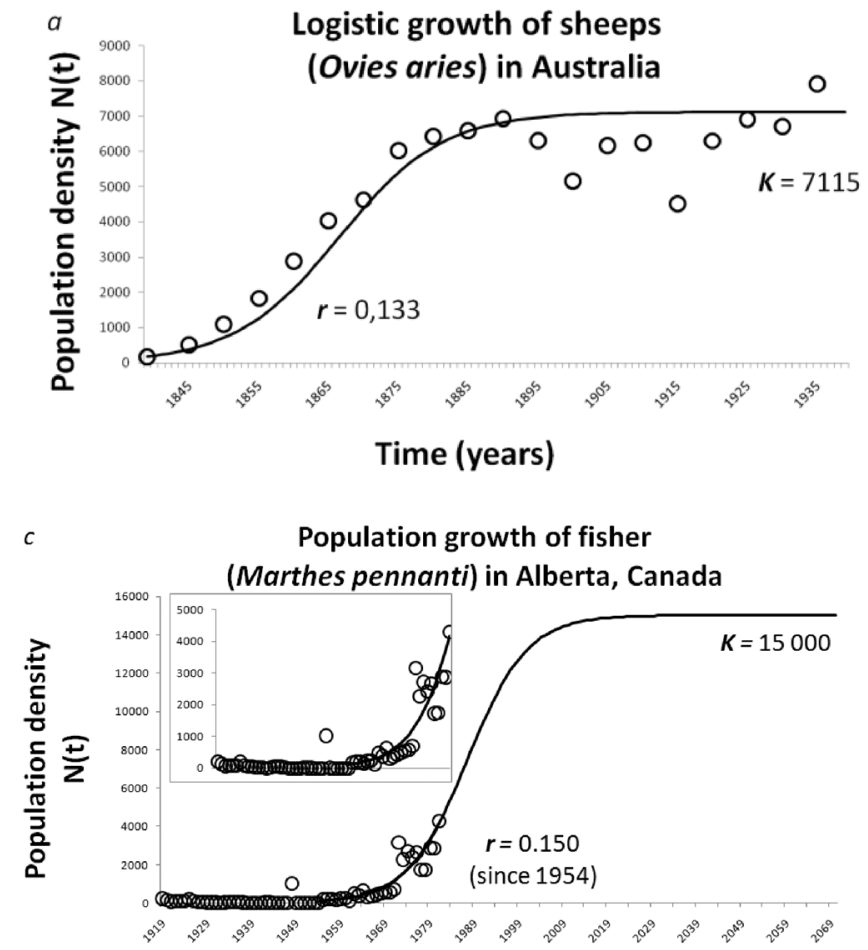

Time (years)

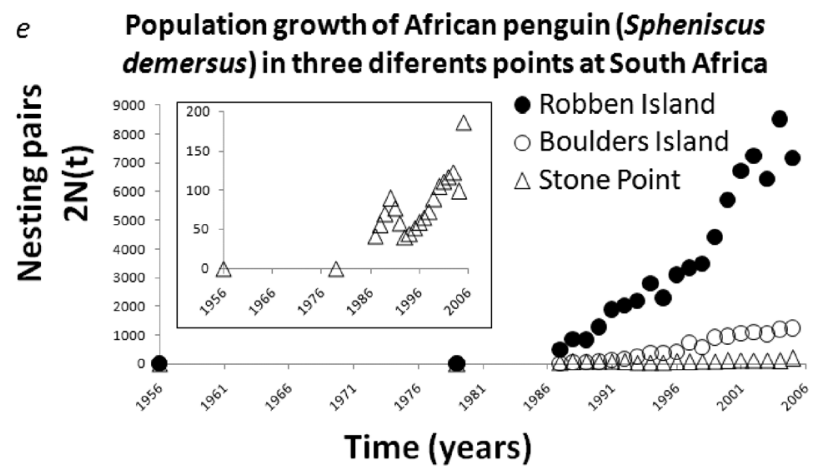

et al., 2006). Red deer (Cervus elaphus) population in Rum Island, Scotland, (Clutton-Brock et al., 1987) showed a different temporal pattern that can be explained from $\theta$-Ricker equation in its discrete form:

$$
N_{i}(t+1)=N_{i}(t) \exp \left[r_{i}\left(1-\frac{N_{i}(t)}{K_{i}}\right)^{\theta}\right]
$$

where $\theta$ the is the intra-specific competition parameter. The calculated parameters were: $N_{0}=44, r=0.40, K=200$ ,$\theta=1.7$. The value of $\theta=1.7$ is an exemple of intense intra-specific competition and this density-dependence factor is one of the determinants in this population (Forchhammer et al., 1998). In this case, the adjusted curve disclosed the intrinsic rate of population growth, the carrying capacity and the exponent of intra-specific competition, population $b$
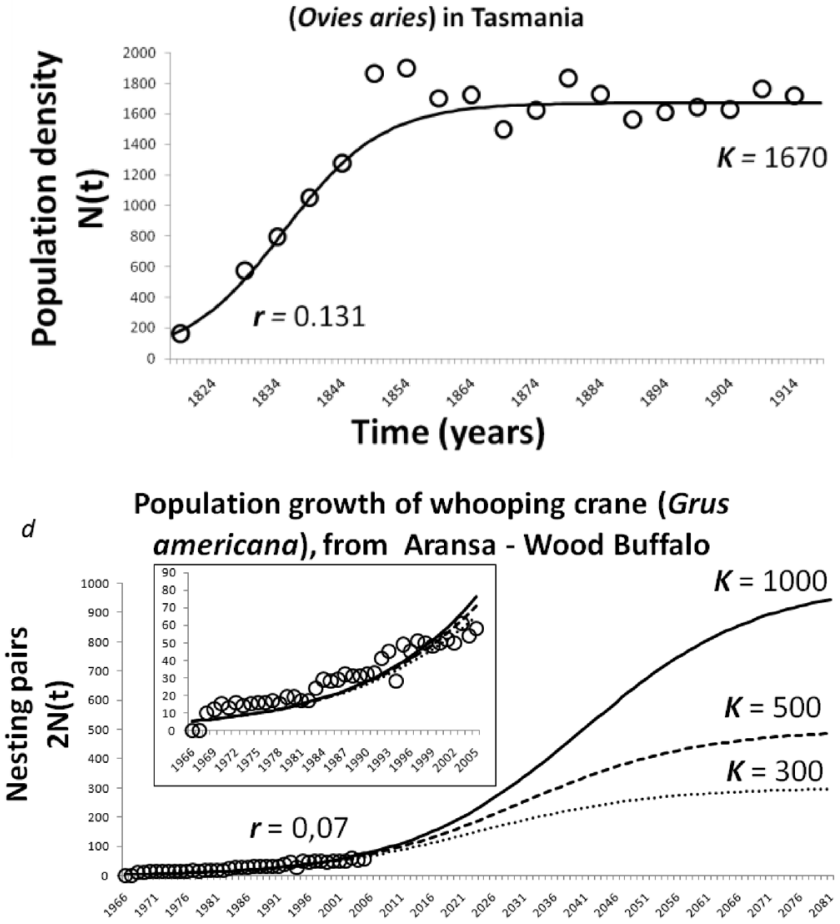

Time (vears)

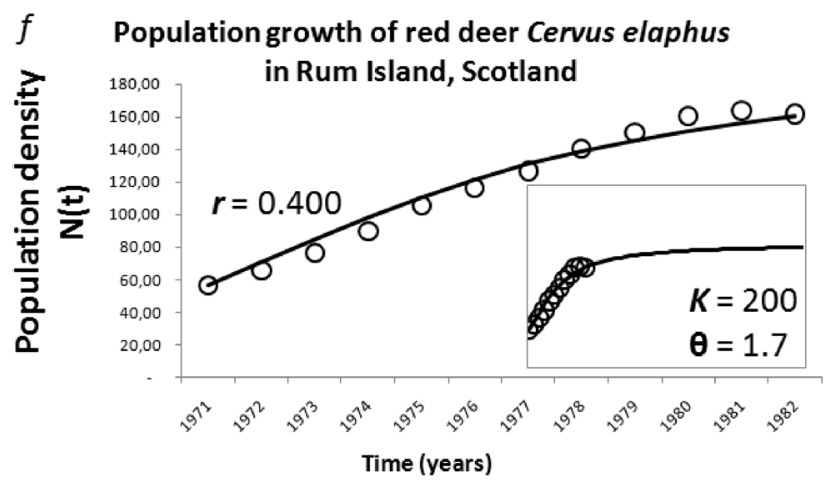

Figure 1-a) Logistic growth of sheep (Ovies aries) introduced in Australia. $\boldsymbol{b}$ ) Logistic growth of sheep (O. aries) introduced in Tasmania. $\boldsymbol{c}$ ) Temporal fluctuation of fisher (Martes pennanti). d) Adjustment of the sigmoid curve to data from monitored populations of whooping crane (Grus americana). $\boldsymbol{e}$ ) African Penguin (Spheniscus demersus) population initial growth for South Africa in three distinct regions: Robben Island, Boulders Island and Stone. $f$ ) Population growth of red deer (Cervus elaphus), an example of high intra-specific competition. 
parameters needed to explain the time series behavior.

Even though species are not found isolated in the environment, a number of natural populations presents sigmoid growth curve. As a rule, however, species interact (technically, they belong to the same food web), are inserted in a biological community, and the community in an ecosystem. There are several ways of interaction among individuals of different populations, being competition or predation the most common. Our common sense tells us that lions do not deplete their prey populations, instead, they select the weakest and/or older prey; sharks do not exhaust their favorite fish stock, as a matter of fact, prey stock is abundant (probably because prey population presents high $r$ and sharks are generalist). Even lynx, a specialist predator, does not exhaust its favorite prey, the Arctic hare.

Lotka (1925) modeled this empirical fact stating the following assumptions: considering $V$ as prey (victim) number and $\frac{d V}{d t}$ variation rate of prey population over time, it is supposed that prey population, when isolated, presents exponential growth described as $\frac{d v}{d t}=r v$, and is regulated by predatory ability. For predation to occur it is strictly necessary that an encounter takes place between prey and predator. If there is a lot of prey and a small number of predators, the chance of capture is very high. And if there are a lot of predators, the prey is quickly exhausted. Predator has a natural ability to capture its prey (predator populations skills optimized through evolutionary mechanisms), and this capacity can also be measured by an attack coefficient. By inserting a number of predators $P$ and multiplying this number by the attack coefficient $\alpha$, we have $a P$ the efficiency of predator population in controlling prey population. By multiplying $a P$ by $V$, we can evaluate how the population of prey will be affected, so:

$$
\frac{d V}{d t}=r V-a P V
$$

Predator relies heavily on prey supply to feed their young, and therefore, population growth depends on how each prey consumed is converted into energy. So introducing the conversion efficiency coefficient $(b)$, as a measure of how much energy prey provides for the sustenance of a singular individual predator. As in prey modeling, encounter between prey and predator is required. The prey population suffers a negative interference determined by the natural mortality increase introduced by predation. So considering $\frac{d P}{d t}=b P V-d P$, you get the resulting system:

$$
\left\{\begin{array}{l}
\frac{d V}{d t}=r V-a P V \\
\frac{d P}{d t}=b P V-d P
\end{array}\right.
$$

Prey population, under certain condition, tends to behave in accordance to the logistic curve, as does any population that depends upon environmental resources. Prey population presents density-dependent regulation and the only biological interference (at least for this simplified model) is the predatory activity. The term density-dependent regulation is exactly the one derived by Verhulst (Fig.2): $\left\{\begin{array}{c}\frac{d V}{d t}=r V\left(\frac{K-V}{K}\right)-a P V \\ \frac{d P}{d t}=b P V-d P\end{array}\right.$

And in the discreet form:

$$
\left\{\begin{array}{c}
V_{t+\mathbf{1}}=N_{t}\left[1+R-\frac{R V_{t}}{K}\right]-\alpha V_{t} P_{t} \\
P_{t+\mathbf{1}}=P_{t}\left[1-d+b V_{t}\right]
\end{array}\right.
$$

By testing the discrete system above, it is possible for the two populations (prey and predator) to coexist, if certain parameters values are ensured. All simulations (Fig. 2a, 2b, 2c, 2d) had fixed values for $R=0.1$ and $K=100$. In Figure $2 \mathrm{a}$, when $a=\mathbf{0}, b=\mathbf{0}, d=\mathbf{0}$ : the prey grows logistically and predator resources are guaranteed. In Figure $2 b$, when $a=0.1, b=0.1, d=0.1$ : a population cycle is established, with the populations eventually collapsing. In Figure $2 \mathrm{c}, b$ conditions are maintained, with the exception of $a a$ value, now 0.01: again there is a cycle with populations presenting very different amplitudes and both going extinct. In Figure 2d, when $R=0.1, K=11, a=0.1, b=0.1$ and $d=0.1$ : conditions required for the maintenance of both populations.

Depending on how parameters are manipulated, population dynamics assume very different behavior, raising the question: Are those dynamics present in nature? The answer is yes, and the classic example of the lynx-hare system may be recalled here (Figure 2e). The population cycle of the American hare and its specialist predator the Canadian lynx is the strongest evidence that predator-prey system really exists in nature. It is currently known that the hare resources growth model (in this case, a plant) has to be included in the system. Keith (1974), created the plant-hare-lynx hypothesis but the cycle determinants are still under study (Krebs et al., 2001, Zhang et al. 2007).

A similar pattern can be seen in the wolf-moose dynamics (Vucetich \& Peterson, 2012) of the Isle Royale, the longest continuous study on any predator-prey system. Some negative interference from abiotic (severe winter causing a collapse on moose population in 1980) and biotic (introduction of a disease from humans in 1996 and intense levels of inbreeding among wolves in 1990s) are known (Fig. 2f).

Detecting population patterns in an ecological system. If a random parameter is inserted in the exponential growth equation in an attempt to simulate some unknown factor affecting directly a population, an approximation to the Malthusian theory of a natural population growth is achieved. This behavior can be visualized in Figure 3. Note that although the population dynamics are unaltered, somehow the noise affects the theoretical population predictability.

In physics the motion of a single gas particle can never be predicted based only on the equations by which they are governed (equations related to mechanics or thermodynamics), because there is an interaction of this particle with several others. To envision this scenario, the motion of a single imaginary ball moving along several others in a pool table 


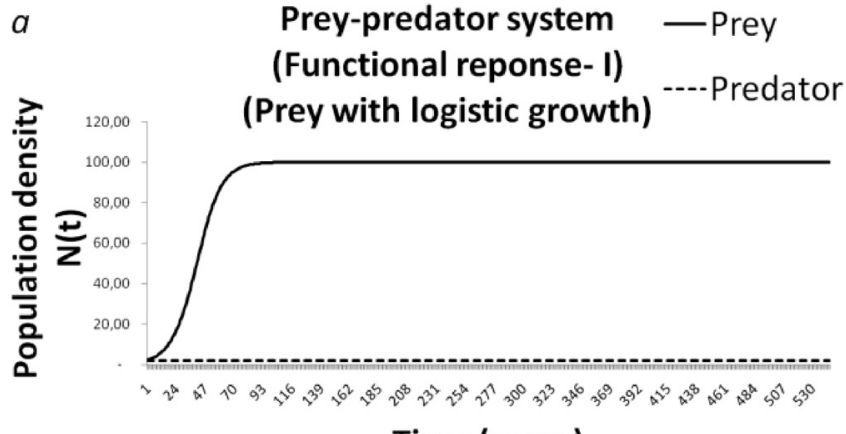

Time (years)
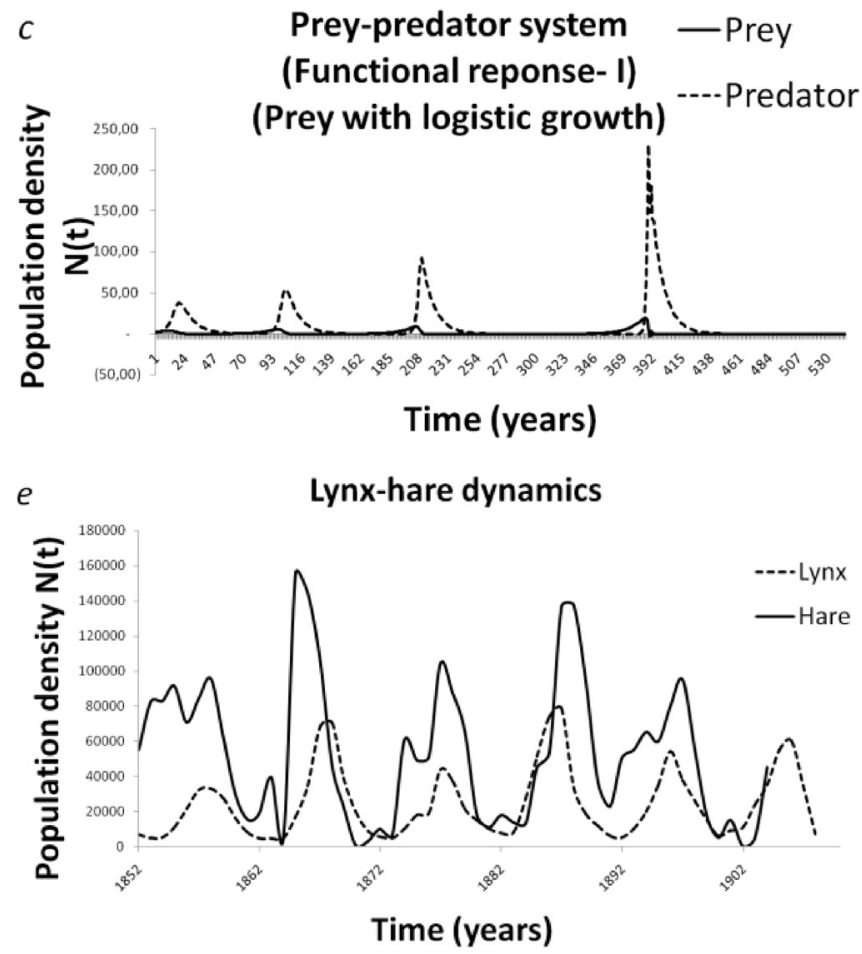
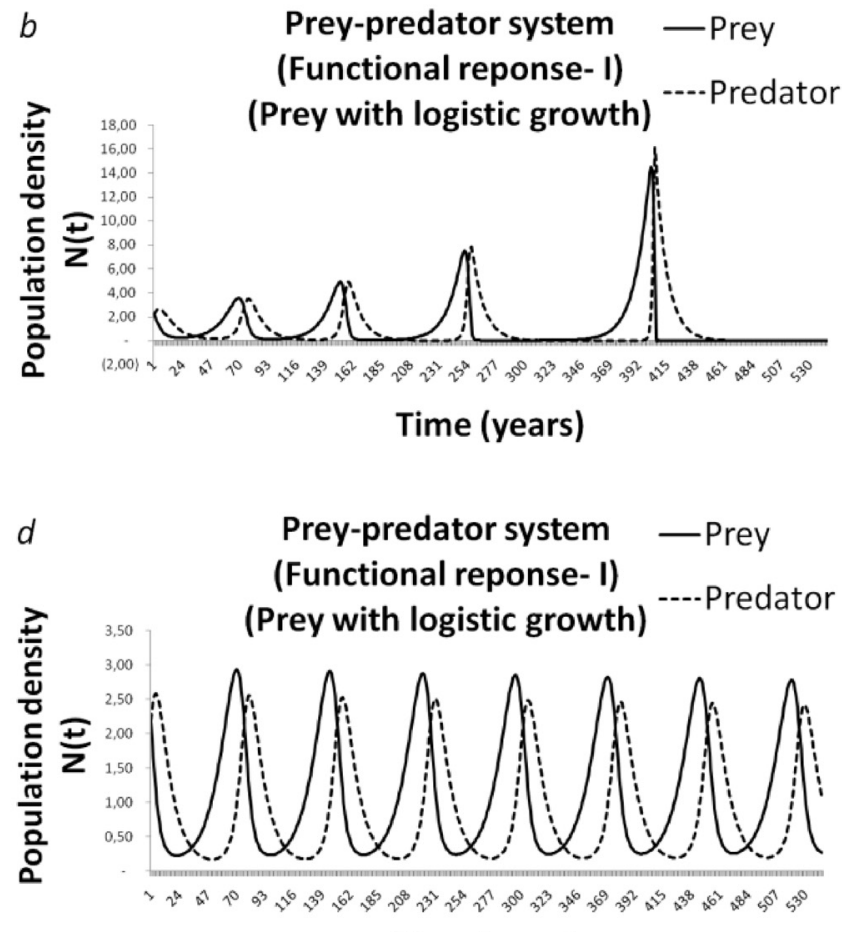

Time (years)

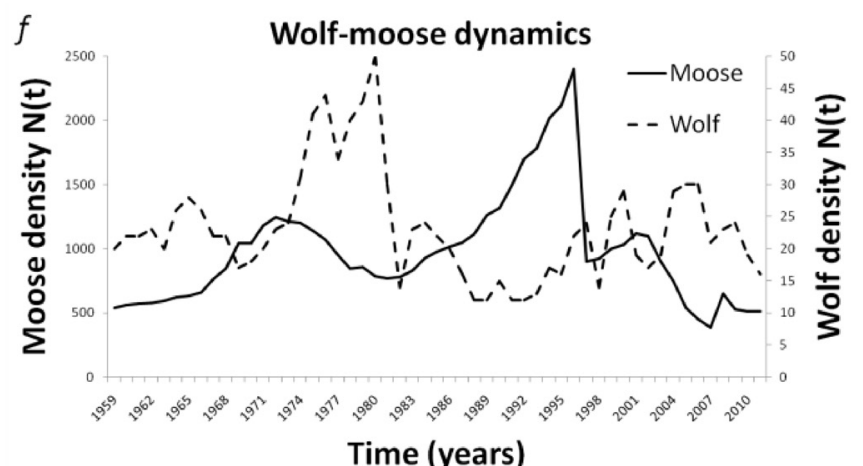

Time (years)

Figure 2 - Discrete Lotka-Volterra predator-prey system, with prey growing logistically. $\boldsymbol{a}, \boldsymbol{b}, \boldsymbol{c}$ and $\boldsymbol{d}$ are different dynamics from different parameters values (see text). In $\boldsymbol{e}$ is the well-knowing lynx-rare trophic oscillation, a real predator-prey dynamics (data from NERC, 2010). $\boldsymbol{f}$ represents the wolf-moose trophic oscillation of Isle Royale (data from Vucetich\& Peterson, 2012).

should be imagined. The single ball would certainly perform a rectilinear motion, but as soon as hit by another ball, its movement would change completely. The prediction of such behavior if attempted would not be met. The greater the number of balls the harder it is to discover the position of the target ball at a given time (and also its speed, acceleration or any other variables). But there will come a time when so many balls will be interacting on the table that all movement will stop. And the system will reach a stable equilibrium.

Hydrologic systems are similar. It is very difficult to predict when it will rain. And the longer the forecasting, more difficult it becomes, because just as with the billiard balls, there are several internal factors (related to the rain phenomenon) added to the external factors (speed wind, unexpected changes in the seasons, air masses, etc..) impossible to control. Hydrological and biological systems are examples among many others presenting little or no control over the variables that regulate them (often it is not even know which variables regulate certain systems).

Hurst (1951) using Nile River level historical records developed an extremely important statistics for complex systems: ${ }^{R}$ analysis. Benoit Mandelbroat, creator of the fractals theory, studying random processes was able to demonstrate, by Gaussian distribution, that a random variable can have its "degree of randomness" measured by the exponent ${ }^{H}$ and that the methodology created by Hurst is useful to characterize random movements occurring over time (Mandelbroat, 1982). This concept is called Fractional Brownian Motion, Fractional Brownian Motion or Fractal Brownian Motion. Mathematically speaking, $B_{H}^{0}(t, w)$, where $B$ is a Brownian random variable that runs in function of time $\left({ }^{t}\right)$ and sample space $\left({ }^{w}\right)$ and $H$ is a fractional value $(0<H<1)$ (Mandelbrot \& Van Ness, 1968).

Hurst saw, analyzing natural phenomena time series such as river flow, rains and temperature, that it mostly follows a 

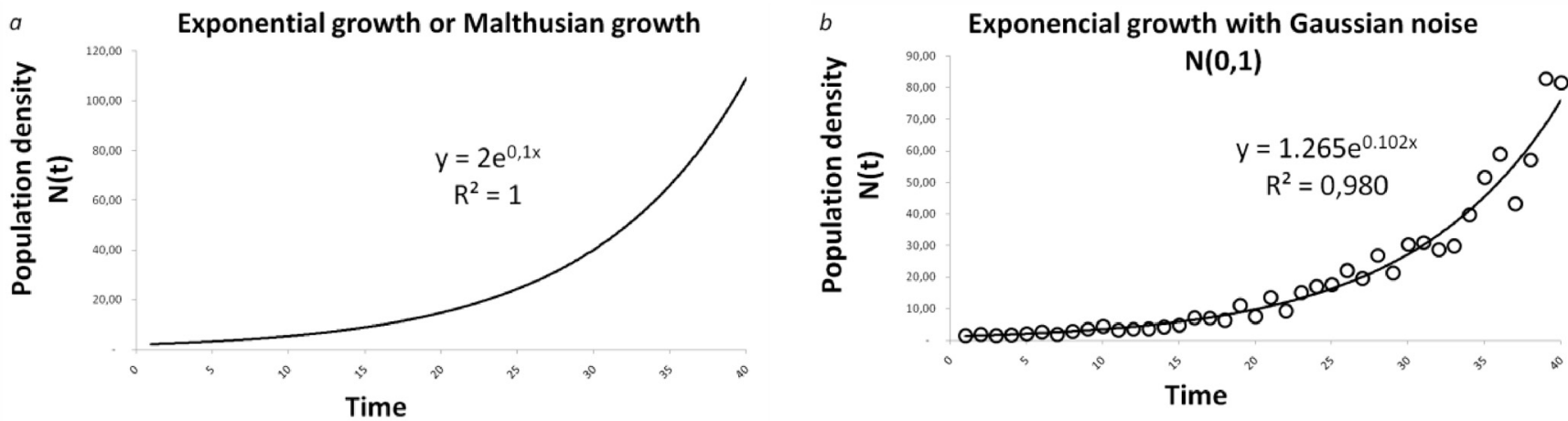

Figure 3- Exponential growth with $r=0.1$ e $N(0)=2$. An exponential adjustment was placed in both figures along with the degree of determination
$R^{\mathbf{2}}: \boldsymbol{a}$ ) exponential growth without noise, $\boldsymbol{b}$ ) exponential growth with stochastic (Gaussian) noise affecting directly the population growth. The adjustment
provided exactly the same exponents, but the degree of adjustment $R^{\mathbf{2}}$, is slightly smaller in $\boldsymbol{b}$.

random walk with bias, a trend with noise. The trend strength and level of noise could be measured by the value $H$. Thus, when the Hurst's exponent is equal to 0.5 , the series is called a random walk and the observations are independent. When $H$ differs from 0.5 , the observations are not independent and contain the memory of preceded events. This is a long-term memory, where the events considered influences distant future events. In other words, systems with ${ }^{H}$ value different from 0.5 resulting from a long chain of interconnected events. $H$ values ranging from 0.5 to 1 , signifies persistent behavior and trends. The strength of biased behavior, or persistent, is a direct function of the ${ }^{H}$ value, i.e., the closer to 1 or $100 \%$ correlation in the equation, the stronger the trend. $H$ values from 0.5 to 0 , signifies anti-persistent behavior and trends (Fig.4).

One of the algorithms reveals that the Hurst exponent (Rescaled Range Analysis or R/S analysis) is an assessment of events that occurred in the past and shows its characteristic value. There are variations in methodology that makes possible analysis in long time windows (1024 sample points) or very short ones (24 points) (Flynn \& Pereira, in preparation). The major problem is that the smaller the time window, the more ephemeral the information "stored" in a series.

Mandelbrot \& Wallis (1969) analyzed several geophysical and hydrological data time series. Annual precipitation in the estuary of St. Laurence in Baltimore, USA, showed $H=0.98$ ; minimal annual of Nile River, $H=0.91$; the annual flow of the Rhine, $H=0.50$ (rare situation), annual flow of the Loire river, $H=0.69$; annual rainfall of Charleston, $H=0.89$. The time series apparently non-predictive showed in most cases $H \neq \frac{1}{2}$, i.e., despite the difficulties in finding satisfactory models to explain such phenomena, the $\frac{R}{S}$ analysis showed that such dynamics hold long-term memories.

Theseconcepts tooksometime to be incorporated inecology. Ariño \& Pimm (1995) applied ${ }^{H}$ for time-series of different organisms densities ( 115 populations from 58 species surveyed annually for at least 25 years). Values ranged $0.25<H<1,13$ with $\bar{H}=0.76$. Among 58 species, 10 presented $H \geq \mathbf{1}$ . Motivated by the possibility of ecological generalizations, the authors separated the species in major groups: land birds, mammals, plants, insects (terrestrial organisms), diatoms and freshwater fish (freshwater organisms) and fish and sea birds (saltwater organisms). This concern is justified, since abiotic factors act differently depending on the environment in which organisms are inserted. The behavior of an abiotic variable can be characterized by noise $\left(\frac{1}{f^{v}}\right)$ being $v$ the noise color. Thus, entirely random fluctuations in frequency and amplitude of population densities are called white noise (with $v=0$ ). Other possibilities are red noise, fluctuations with low frequency and high amplitude, and blue noise, fluctuations with high frequency and high amplitude. There is a relationship between the values of $v$ and ${ }^{H}$, expressed by $v=2 H-1$ (this concept is extensive and will not be treated here, but can be checked in Halley, 1996 and Halley \& Inchausti, 2004). For example, marine systems present a strong red spectrum while terrestrial systems, a white noise (Steele, 1985). For terrestrial vertebrates (birds and mammals) and insects separated into species groups with cyclic and non-cyclic population behavior also showed significant differences: non-cyclic vertebrates, $\bar{H}=0,87$; non-cyclic insects, $\bar{H}=0,68$; cyclic vertebrates, $\bar{H}=0,64 ;$ and cyclic insects, $\bar{H}=0,34$.

The intrinsic rate of natural population growth, a fundamental parameter to feed models, is hardly obtainable from empirical data (Lynch \& Fagan 2009, Fagan et al., 2010). Fenchel's law (Fenchel, 1974), allometric relation between average body mass and $r_{\max }$ (intrinsic rate of population when biotic and abiotic conditions are optimal), works well for some groups of organisms, however there are no studies that have generate enough data to allow generalizations (Fagan et al., 2010).

Keitt \& Stanley (1998) analyzed North American bird data from annual abundance inventory encompassing 31 years and over 3000 routes. The population growth rate of specie $s,{ }^{R_{s}(t) \square} \frac{N_{s}(t+1)}{N_{s}(t)}$, was analyzed. The rate $r$ is a multiplicative parameter in statistical sense, the difference between birth and mortality in a population $(b-d=r)$ is affected by various biotic and non biotic factors. Although some authors affirm thatthe population abundance distribution follows a log-normal distribution, Keitt and Stanley showed that this distribution can be defined as a power law $P\left(R_{S}\right) \propto R_{S}{ }^{\alpha}$ if $R_{S} \leq 1$ and $P\left(R_{S}\right) \propto R_{S}^{-\infty}$ if $R_{S} \geq \mathbf{1}$, emerging a characteristic exponent, 

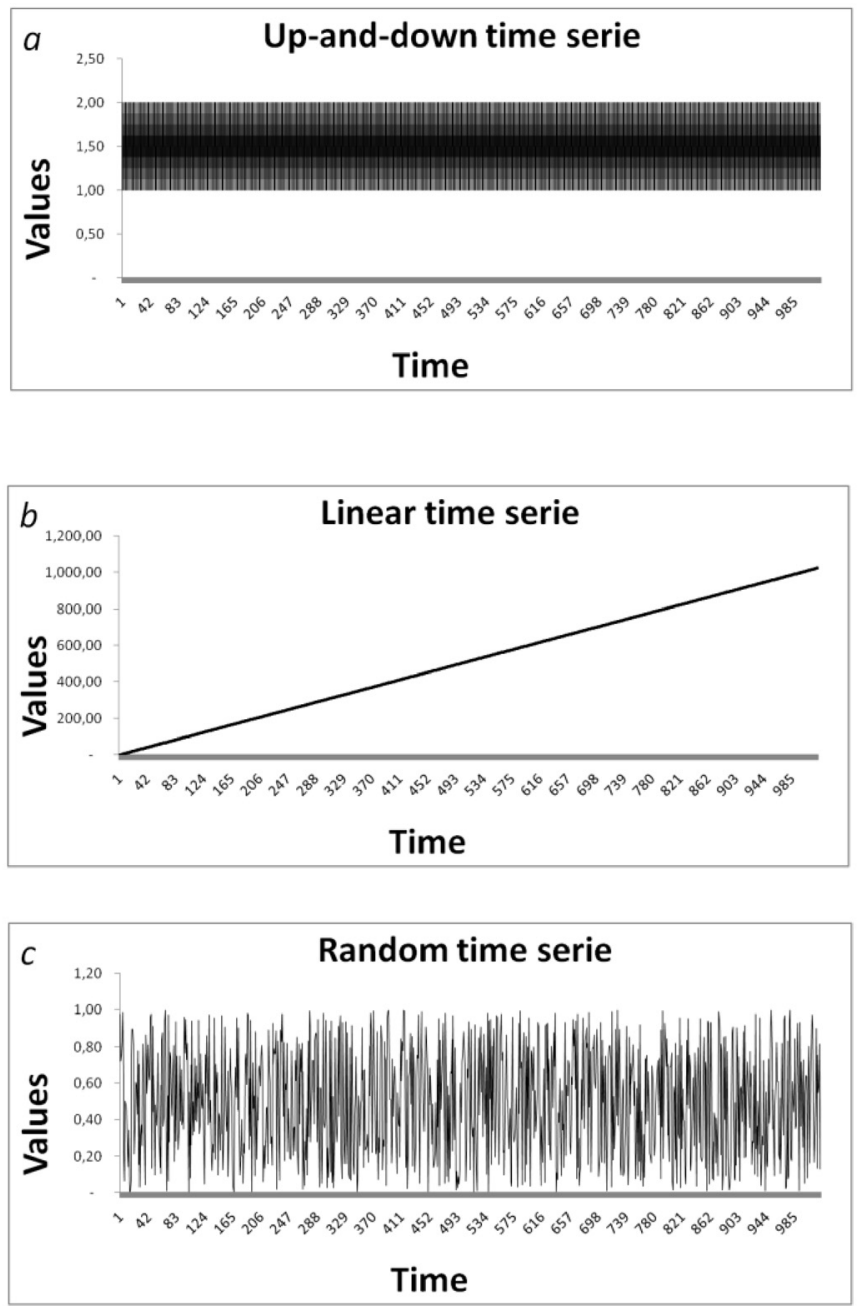

Figure 4-Types of time series and respective $H$ values. $a$ ) anti-persistent series with $H=0.004 ; \boldsymbol{b}$ ) persistent series with $H=1.006 ; \boldsymbol{c}$ ) random series with $H=0.536$

$\boldsymbol{\alpha}=2$. So the authors applied the $r \equiv \log R_{s}$ approach transforming the previous relations in $P\left(r_{s}\right) \propto \exp ^{-\alpha\left|r_{s}\right|}$. And interestingly enough, population abundances covering all analyzed data respected this relationship. Having the time series of two measures, $R_{S}(t)$ and $r_{S}(t)$ the authors arrived at $H=0.14$, evidencing a anti-persistent behavior. The authors did not make clear if this is a species-specific value or if it corresponds to the generalization made above.

Ariño \& Pimm (1995) and Keitt \& Stanley (1998) worked with data from natural populations under diverse biotic and abiotic noises. The authors were able to provide evidence that monitored population abundances may reveal some degree of predictability and further key information.

For populations maintained in laboratory, Miramontes \& Rohani (1998) found $H=0.22$ for blowflies, $H=0.15$ for the beetle called bean weevil and $H=0.14$ for its parasitoid (the insect that hosts the beetle eggs), denoting an anti-persistent behavior. There are anti-persistence in time series of controlled populations and we can easily infer that consumer-resource systems control the cyclical behavior of interacting species.
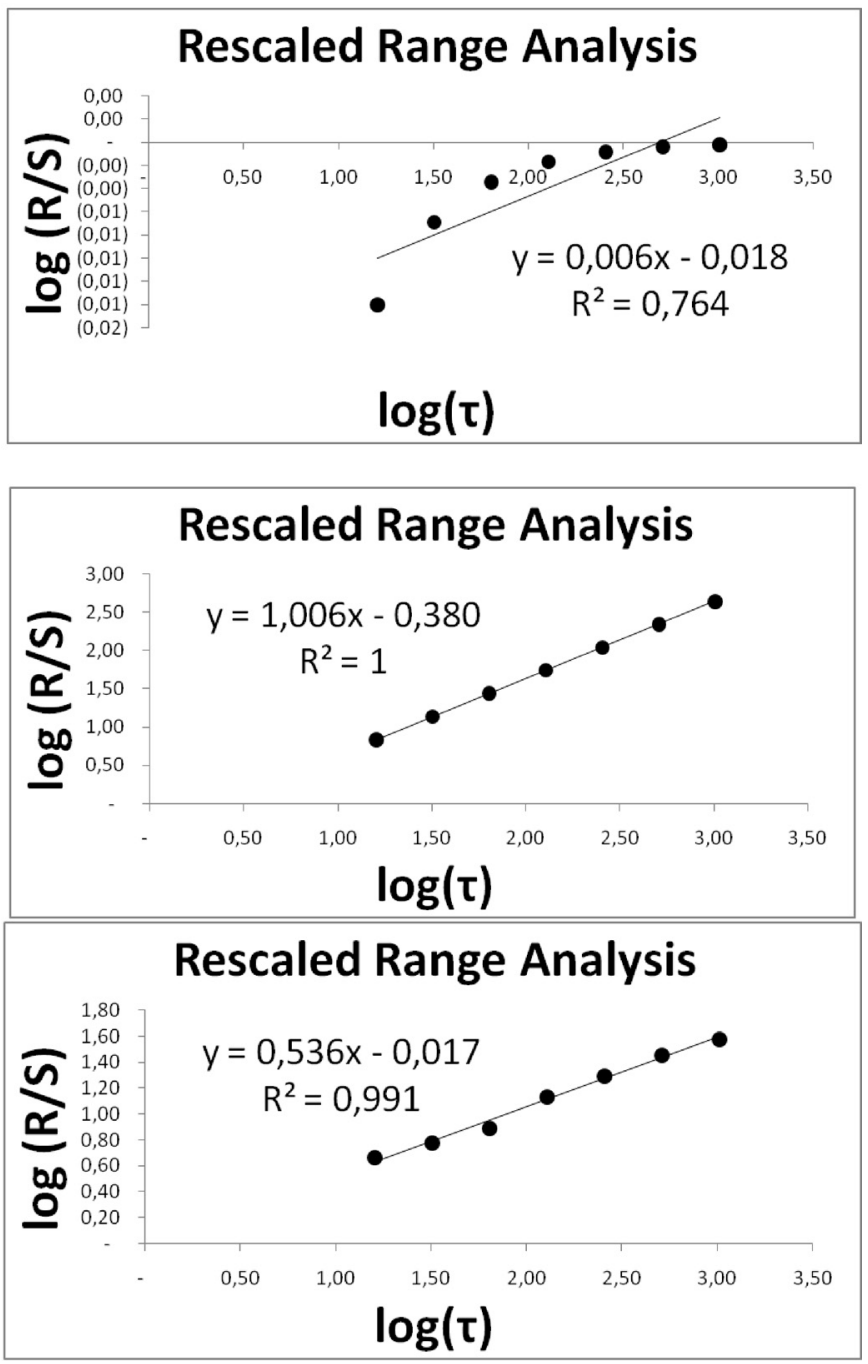
exponentially adjusting the new series, the adjustment exponent takes the same value of $r$, previously defined. And the calculated value for the Hurst exponent is $H=1.054$ (Fig. $5 c)$. This finding is in accordance with the Halley \& Stergiou (2005) interpretation justifying $H$ increase in commercial fish temporal series associated with the exponential growth of populations in captivity.

While exponentially adjusting this series, the exponent revealed, curiously, value equal to $r=0.0025$. By using the exponential series under a Brownian noise, and calculating again Hurst exponent, the value generated was $H=1.064$. It can be concluded that a population growing exponentially in a very noisy environment generates a continuing trend, when the natural growth intrinsic rate is intense enough to overcome all noises interfering with its dynamics. This finding supports the results of Halley \& Stergiou (2005).

\section{CONSIDERATIONS}

Several lines of evidence suggest that the effects of stressors on populations can be calculated accurately by population modeling. A wide variety of population models have been used integrating more or less biological details related to population class structure, physiological responses, density factors, stochasticity, and spatial information.

The understanding of population dynamics is derived from strictly biological or ecological principles transformed into mathematical parameters governing the behavior of certain equations along the time (Caswell, 2001; Noel et al., 2006; Jager \& Klok 2010; Kramer et al., 2011).

There is no general law covering the dynamics of all organisms established in the globe's various ecosystems, but there are many evidences of the existence of rules governing the behavior of

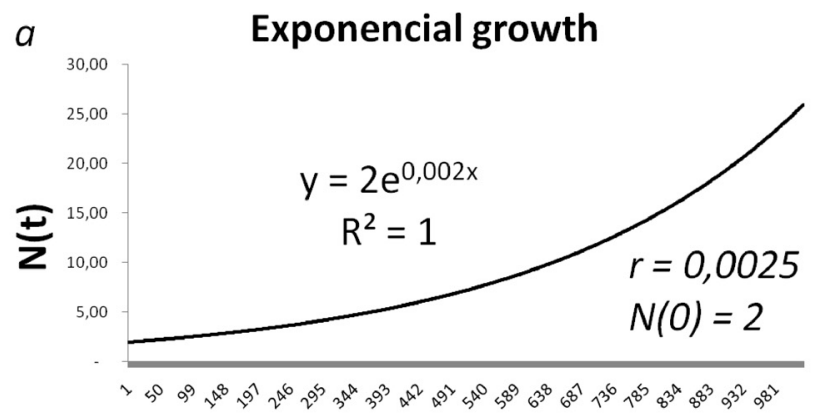

Time

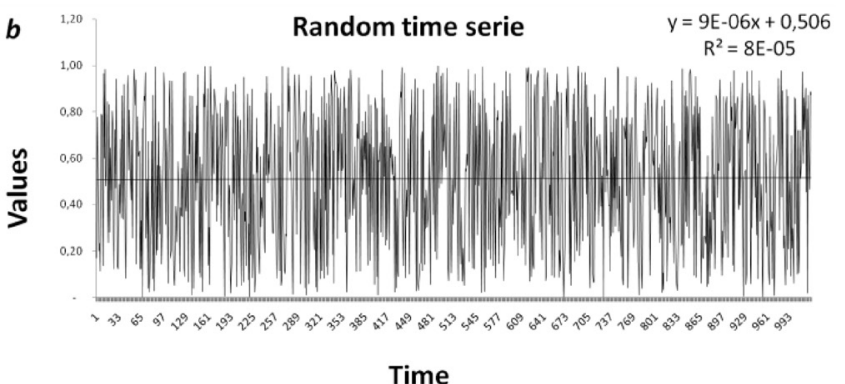

Time

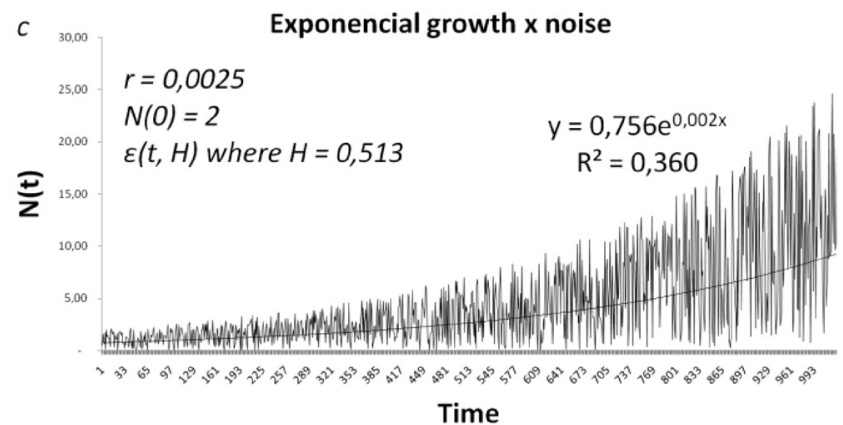

R/S Analysis (noise)

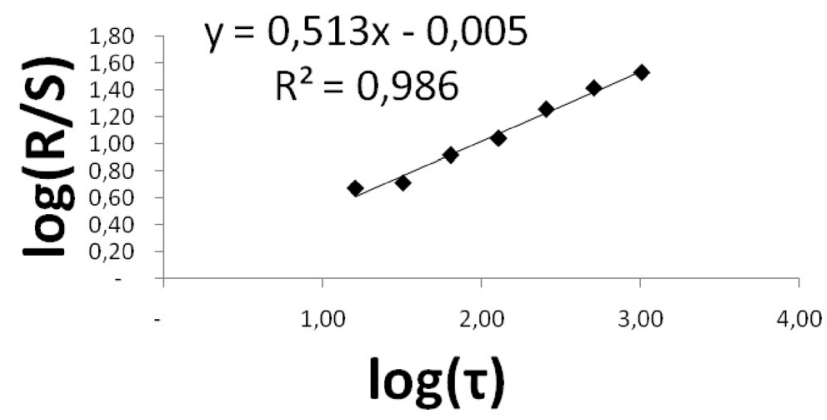

R/S Analysis (exponencial growth with noise)

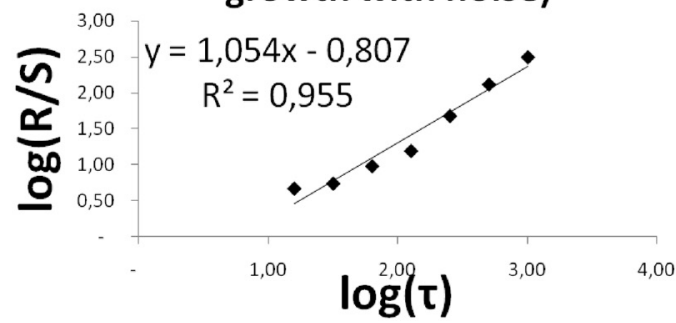

Figure 5 -Exponential growth representation of a theoretical population in a noisy environment. $\boldsymbol{a})$ Exponential growth with $r=0,0025$ and $N(\mathbf{0})=2$ b) Hurst exponent value for generated noise was $H=0,513$, i.e., Brownian. $c$ ) When the noise was applied to the exponential growth in the form, $(t)=N(0) e^{r t} \in(t, H)$, it arose the temporal behavior shown on the graph. 
populations growth, the establishment of carrying capacity and density fluctuations related to consumer-resource ratios besides extinction risk, all useful population level endpoints (Barnthouse et al., 2007; Munns et al., 2008; Pastorok et al., 2002; Thorbek et al., 2009; Wang \& Grimm, 2010).

Population responses to environmental stress have been assessed in terms ofeffects on: population growth rate based on an analysis of the way that the rate declines as stress increases; the carrying capacity of a study environment, defined as the value of population density at which population growth is zero. Knowledge of how carrying capacity is affected by stress is crucial to understanding how natural populations are affected by stress (Sibly et al., 2000); population density, especially for short-term effects, is a direct indicator of how changes of demographic parameters accumulate at the population level (Noel et al., 2006); and population viability, in terms of extinction risk or quasi-extinct risk (Holmes et al., 2007; Sabo \& Gerber, 2007).

Considering all the conceptual technology, the statistical and mathematical development, the empirical evidence, allied to the Population Ecology development, it probably could be said that despite the fact that ecology does not present compelling general laws, it is endowed with a series of models that describes effectively population behavior and presents statistical tools that allow us to analyze and control random processes. Therefore, a natural population can present standards like the ones provided by Turchin principles and any environmental stress is perceived as such when the expected behavior does not occur. Nevertheless populations immersed in extremely complex systems, potentially undergoìng several abiotic and biotic interferences, and revealing values of $H=\frac{1}{2}$, lead us to believe that they are difficult (if not impossible) to be modeled.

For the modeling of a natural population and the establishment of population endpoints, a starting point undoubtedly should be the equation of Ricker (discrete version that simulates Verhulst logistic growth),

$$
N_{i}(t+1)=N_{i}(t) \exp \left[r_{i}\left(1-\frac{N_{i}(t)}{K_{i}}\right)\right]
$$

Then, the theoretical behavior of competing species can be simulated, based on Kilpatrick \& Ives (2003), by using the Ricker equation plus the interspecific competition coefficient that simulates the effect of competition on the species ${ }^{i}$, and also the inclusion of a random variable, $\epsilon_{i}(t)$.

$$
N_{i}(t+1)=N_{i}(t) \exp \left[r_{i}\left(1-\frac{N_{i}(t)+\sum_{j \neq i} \alpha_{i j} N_{j}(t)}{K_{i}}\right)+\epsilon_{i}(t)\right]
$$

Kilpatrick \& Ives'smodel could be modified by inserting a few more parameters and improvement of the random process (abiotic parameter). This model assumes the following form:

$$
N_{i}(t+1)=N_{i}(t) \exp \left[r_{i}\left(1-\frac{N_{i}(t)+\Sigma_{j \neq} a_{i j} N_{j}(t)}{\left[K_{i}+k_{i}\left[\cos \left(\frac{2 \pi t}{C_{1}}\right)\right]\right] \epsilon(t, H)}\right)^{\theta}\right]
$$

Adopting the inclusion of one more ecological parameter $\theta$, exponent of intraspecific competition, and altering ${ }^{K_{i}=K_{i}+k_{i}\left[\cos \left(\frac{2 \pi t}{c_{1}}\right)\right]}$
(May, 1976b), term that simulates an oscillatory behavior in $K$ and $\epsilon(t, H)$ acting directly on the considered carryingcapacity. Alternatively it could also be $\epsilon(t, H)$, i.e., make the random variable act in function $H$. The evolution ofthe model can be seen in Figure 6 for three competing species growing logistically, with a term that simulates oscillatory behavior in $K$. The random variable $\epsilon$ is a function of time and may have its persistence / anti-persistence / randomness measured by the Hurst exponent (i.e., $\epsilon(t, H)$ and acts directly on $K$. For the different species values of $r, K$ and $\alpha_{i j}$ are: $r_{\mathbf{1}}=0.5$ $, r_{2}=0.5, r_{3}=1, K_{1}=5000, K_{2}=2000, K_{3}=2000$, $\alpha_{1 \mathrm{z}}=0.1, \alpha_{1 \mathrm{a}}=0.1, \alpha_{21}=0.1, \alpha_{2 \mathrm{a}}=0.1, \alpha_{31}=0.5$, $\alpha_{32}=0.5$. And the possible outcomes are: a) the three species becomes extinct because the interference from other species are too high; b) Oscillatory behavior on $K_{\mathbf{1}}, K_{\mathbf{2}}$ and $K_{\mathbf{2}}$, with $k_{1}=25 \% K_{1}, k_{2}=50 \% K_{2}$ and $k_{\mathrm{a}}=10 \% K_{\mathrm{a}}$ and $c_{1}=10$ ,$c_{\mathbf{2}}=30$ and $c_{\mathbf{3}}=60$ (note that the $\mathbf{x}$ axis comprehends $\Delta t=60$ and the $\frac{\Delta t}{c_{\text {especice }}}$ values reveals the cycle length if the initial population $\left.N(0)_{e s p e ́ c i e}=K_{e s p e ́ c i e}\right)$. c) Insertion of a Gaussian noise on $K$ value of each of the three species. d) Insertion of a Brownian noise on $K$ value of each species. Different values for parameters was not tested here, therefore, $\theta_{\mathbf{1}}=\theta_{\mathbf{2}}=\theta_{\mathbf{3}}=\mathbf{1}$ was considered. Note that the Gaussian or Brownian random variable influences the dynamics of the three species, and Brownian noise significantly alter the cyclical behavior of populations.

If the monitored population presents $H^{*} \frac{1}{2}$, this may be a sign that its environment is very complex. If the monitored population changes its dynamics showing any one of Turchin patterns, it can be concluded that some alteration occurred in the ecosystem so that the population develops another dynamic. Eventually the pattern can return to the initial one or not, assuming another (for example, the ramp-shaped curve generated by the equation of Hassell, widely used in entomology, or growth followed by a sharp drop generated for certain values of $\theta$ in the equation Teta-Ricker).

Models of population-level effects of stress can integrate information from lower levels of biological organization and feed that information into higher-level community and ecosystem models. Population-level responses integrate the cumulative effects of stressors on population individuals as those individuals interact with and are affected by their cospecifics, competitors, predators, prey, habitat, and other biotic and abiotic factors (Kramer et al., 2011).

Methods in impact assessment includes, as first-tier assessments the application of standardized safety factors to endpoints derived from laboratory studies such as acute mortality and measures of individual lifetime reproductive success, besides traditional community assessments such as the use of structural parameters (species richness, diversity, abundance and eveness). Higher-tier assessments, such as population modeling, should be employed when the firsttier assessments suggest potentially unacceptable risk to the individuals and by extension the populations under consideration. Population models can even be employed to generalize the results of higher tier studies to other landscapes 
$a$

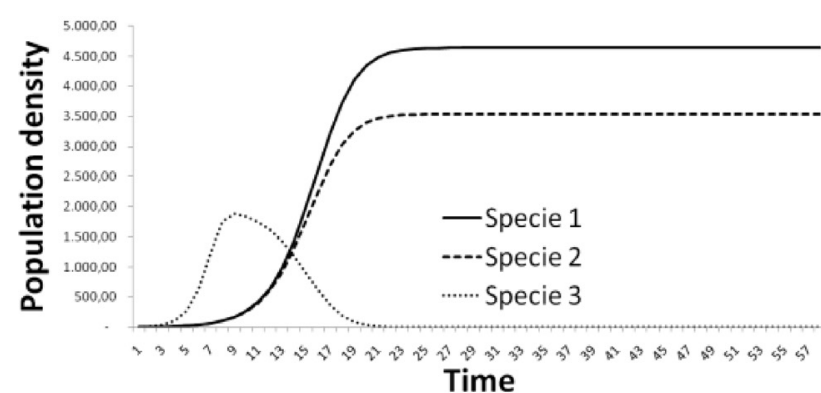

c Three species competition with periodic cycle in carrying capacity and Gaussian noise

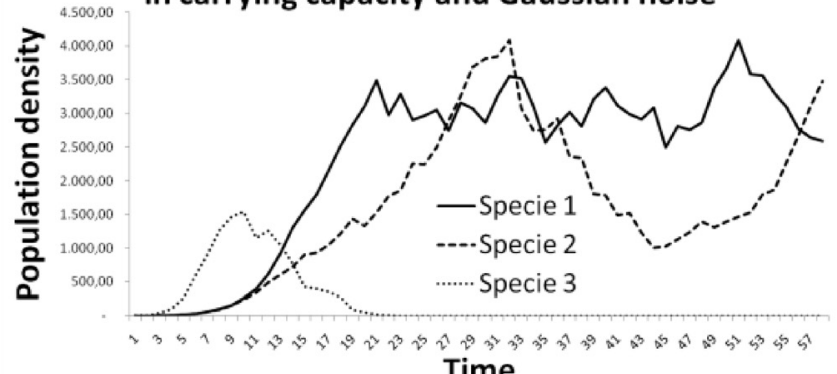

$b \quad$ Three species competition with periodic cycle in carrying capacity

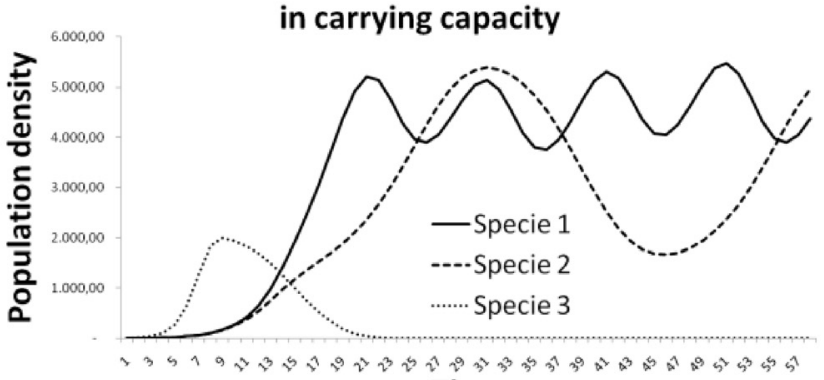

Time
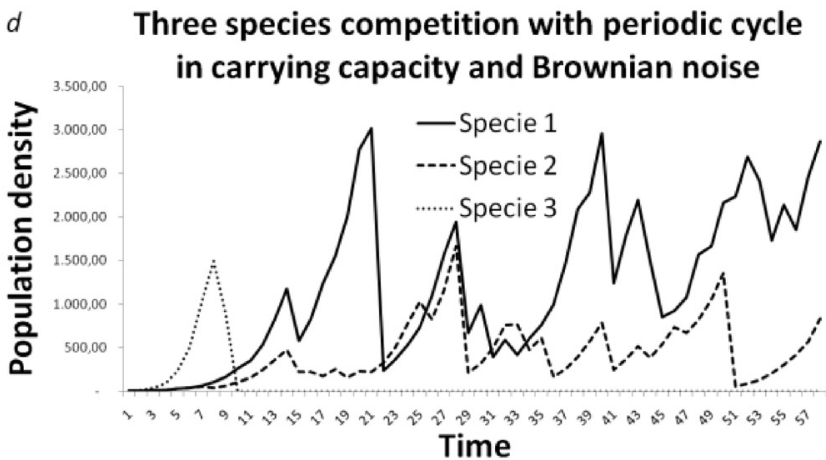

Figure 6- Model evolution for a three competing species growing logistically system, with the simulation of oscillatory behavior in $K$. $a$ ) The third species becomes extinct. $\boldsymbol{b}$ ) Insertion of the oscillatory behavior on $K_{\mathbf{1}}, K_{\mathbf{2}}$ and $K_{\mathbf{3}}$. c) Insertion of a Gaussian noise on $K$ of the three species. $\boldsymbol{d}$ ) Insertion of a Brownian noise on $K$ of each species. All species receive the same noise.

and exposure situations and, in the absence of higher-tier studies, provide a means of translating individual-level study results to population-level responses (Kramer et al., 2011).

\section{ACKNOWLEDGEMENTS}

We are grateful to Dra. Gisela de Aragão Umbuzeiro for the suggestions and careful review of the manuscript.

\section{REFERENCES}

ARIÑO, A. \& PIMM, S. L. 1995. On the nature of population extremes. Evol. Ecol. 9: 429-443. http://dx.doi.org/10.1007/ BF01237765

BARNTHOUSE, L. W., MUNNS, W. R. \& SORENSON, M. T. 2007. Population-Level Ecological Risk Assessment. Taylor \& Francis, Boca Raton, Florida, U. S. A.

CANADIAN WILDLIFE SERVICE AND U.S. FISH AND WILDLIFE SERVICE. 2005. International recovery plan for the whooping crane. Ottawa: Recovery of Nationally Endangered Wildlife (RENEW), and U.S. Fish and Wildlife Service. Albuquerque, New Mexico. $162 \mathrm{pp}$.

CASWELL, H. 2001. Matrix Population Models. 2nd edn. Sinauer Associates, Sunderland, MA.

CLUTTON-BROCK, T. H., ALBON, S. D. \& GUINNESS, F. E. 1987. Interactions between population density and maternal characteristics affecting fecundity and juvenile survival in red deer. J. Anim. Ecol. 56: 857-871.

DAVIDSON, J. 1938A. On the ecology of the growth of the sheep population in South Australia. Trans. Roy. Soc. S. A., 62 (1): 11-
148.

DAVIDSON, J. 1938B. On the growth of the sheep population in Tasmania. Trans. Roy. Soc. S. A., 62 (2): 342-346.

FAGAN, W. F., LYNCH, H. J. AND NOON, B. R. 2010. Pitfalls and challenges of estimating population growth rate from empirical data: consequences for allometric scaling relations. Oikos, 119: 455-464. http://dx.doi.org/10.1111/j.1600-0706.2009.18002.x

FENCHEL, T. 1974. Intrinsic rate of natural increase: the relationship with body size. Oecologia, 14: 317-326. http:// dx.doi.org/10.1007/BF00384576

FLYNN, M. N. \& PEREIRA, W. R. L. S. 2013. Ecological diagnosis from biotic data by Hurst exponent and the R/S analysis adaptation to short time series. In preparation.

FORCHHAMMER, M. C., STENSETH., N. C., POST, E \& LANGVATN, R. 1998. Population dynamics of Norwegian red deer: density-dependence and climatic variation Proc. R. Soc. Lond. B., 265, 341-350. http://dx.doi.org/10.1098/ rspb.1998.0301

HALLEY, J. M. 1996. Ecology, evolution and 1/f-noise. Trends Ecol. Evol., 11: 33-37. http://dx.doi.org/10.1016/01695347(96)81067-6

HALLEY, J. M. \& INCHAUSTI, P. 2004. The increasing importance of 1/f-noises as models of ecological variability (review). $F N L$, 4: R1-R26. http://dx.doi.org/10.1142/S0219477504001884

HALLEY, J. M. \& STERGIOU, K. I. 2005. The implications of increasing variability of fish landings. Fish Fish., 6: 266-276. http://dx.doi.org/10.1111/j.1467-2979.2005.00188.x

HASSELL, M. P., LAWTON, J. H., \& MAY, R. M. 1976. Patterns of dynamical behavior in single species populations. J. Anim. Ecol., 45: 471-486.

HOLMES, E. E., SABO, J. L., VISCIDO, S. V., FAGAN, W. F. 2007. A statistical approach to quasi-extinction forecasting. 
Ecol. Lett., 10: 1182-1198. http://dx.doi.org/10.1111/j.14610248.2007.01105.x

HURST, H. E. 1951. Long-term storage capacity of reservoirs. Trans. Am. Soc. Civ. Eng., 116: 770-808.

JAGER, T. \& KLOK, C. 2010. Extrapolating toxic effects on individuals to the population level: the role of dynamic energy budgets. Phil. Trans. R. Soc. B, 365: 3531-3540. http://dx.doi. org/10.1098/rstb.2010.0137

KEITH, L. B. 1974. Some features of population dynamics in mammals. In 11th Int. Congr. of Game Biologists. National Swedish Environment Protection Board, Kjerner, I. \& Bjurholm, P. (eds), Stockholm. p. 17-58.

KEITT, T. H. \& STANLEY, H. E. 1998. Dynamics of North American breeding bird population. Nature, 393: 257-260. http:// dx.doi.org/10.1038/30478

KILPATRICK, A. M. \& IVES, A. R. 2003. Species interactions can explain Taylor's power law for ecological time series. Nature, 422: 65-68. http://dx.doi.org/10.1038/nature01471

KRAMER, V. J., ETTERSON, M. A., HECKER, M., MURPHY, C. A., ROESIJADI, G., SPADE, D. J., SPROMBERG, J. A., WANG, M. \& ANKLEY, G. T. 2011. Adverse outcome pathways and ecological risk assessment: bridging to population-level effects. Environ. Toxicol. Chem., 30(1): 64-76. http://dx.doi. org/10.1002/etc. 375

KREBS, C. J., BOONSTRA, R., BOUTIN, S. \& SINCLAIR, A. R. E. 2001. What drives the 10-year cycle of snowshoe hares? BioScience, 51: 25-35. http://dx.doi.org/10.1641/00063568(2001)051[0025:WDTYCO]2.0.CO;2

LOTKA, A. J. 1925. Elements of physical biology. Baltimore: Williams \& Wilkins Co.

LYNCH, H. J \& FAGAN, W. F. 2009. Survivorship curves and their impact on the estimation of maximum population growth rates. Ecology, 90(4): 1116-1124.

MALTHUS, T. R. 1798. An essay on the principle of population. J. Johnson, London.

MANDELBROT, B. B. \& VAN NESS, J. W. 1968. Fractional Brownian Motions, Fractional Noises and Applications. SIAM Rev., 10 (4): 422-437. http://dx.doi.org/10.1137/1010093

MANDELBROT, B. B. \& WALLIS, J. R. 1969. Some long-run properties of geophysical records. Water Resour. Res., 5: 321340. http://dx.doi.org/10.1029/WR005i002p00321

MANDELBROT, B. B. 1982. The fractal geometry of Nature. W. H. Freeman and Company, San Francisco.

MAY, R. M. 1976A. Simple mathematical models with very complicated dynamics. Nature, 261: 459-467. http://dx.doi. org/10.1038/261459a0

MAY, R. M. 1976B. Models for single populations. In Theoretical Ecology: Principles and Applications. May, R. M. (ed.), W. B. Saunders, Philadelphia.

MIRAMONTES, O. \& ROHANI, P. 1998. Intrinsically generated coloured noise in laboratory insect populations. Proc. R. Soc. Lond. B, 265: 785-792. http://dx.doi.org/10.1098\%2Frspb.1998.0361

MUNNS, W. R., GERVAIS, J., HOFFMAN, A. A., HOMMEN, U., NACCI, D. E., NAKAMARU, M., SIBLY, R. \& TOPPING, C. J. 2008. Modeling approaches to population-level ecological risk assessment. In Population-Level Ecological Risk Assessment, BARNTHOUSE, L. W., MUNNS, W. R. \& SORENSON, M. T., Eds, CRC, Boca Raton, FL, USA, pp. 179-210.

NERC Centre for Population Biology, Imperial College. 2010. The
Global Population Dynamics Database Version 2.

NOËL, H. L., HOPKIN, S. P., HUTCHINSON, T. H., WILLIAMS, T. D. \& SIBLY, R. M. 2006. Towards a population ecology of stressed environments: the effects of zinc on the springtail Folsomia candida. J. Appl. Ecol., 43: 325-332. http://dx.doi. org/10.1111/j.1365-2664.2006.01133.x

NOVAK, M., BAKER, J. A., OBBARD, M. E. \& MALLOCH, B. 1987.Wild Furbearer Management and Conservation in North America.Ontario Trappers Association, North Bay, Ontario.1168 pp.

PASTOROK, R. A., BARTELL, S. M., FERSON, S. \& GINZBURG, L. R. 2002. Ecological Modeling in Risk Assessment: Chemical Effects on Populations, Ecosystems, and Landscapes, CRC, Boca Raton, FL, USA.

PEARL, R., 1925. The Biology of Population Growth, Knopf, New York.

SABO, J. L. \& GERBER, L. R. 2007. Predicting extinction risk in spite of predator-prey oscillations. Ecol. Appl., 17: 1543-1554. http://dx.doi.org/10.1890/06-0630.1

SIBLY, R. M., WILliAMS, T. D. \& JONES, M. B. 2000. How environmental stress affects density dependence and carrying capacity in a marine copepod. J. Appl. Ecol., 37: 388-397. http:// dx.doi.org/10.1046/j.1365-2664.2000.00534.x

STEELE, J. H. 1985. A comparison of terrestrial and marine ecological systems. Nature, 313: 355-358. http://dx.doi.org/ doi: $10.1038 / 313355 \mathrm{a} 0$

THORBEK, P., FORBES, V. E., HEIMBACH, F., HOMMEN, U., THULKE, H-H., VAN DEN BRINK, P. J., WOGRAM, J. \& GRIMM, V. 2009. Ecological Models for Regulatory Risk Assessments of Pesticides: Developing a Strategy for the Future. SETAC, Pensacola, FL, USA.

TURCHIN, P. 2001. Does population ecology have general laws? Oikos, 94: 17-26. http://dx.doi.org/10.1034/j.16000706.2001.11310.x

UNDERHILL, L. G., CRAWFORD, R. J. M., WOLFAARDT, A. C., WhitTINGTON, P. A., DYER, B. M., LESHORO, T. M., RUTHENBERG, M., UPFOLD, L. \& VISAGIE, J. 2006. Regionally coherent trends in colonies of African penguins Spheniscus demersus in the Western Cape, South Africa, 19872005. Afr. J. Marine Sci., 28(3\&4): 697-704. http://dx.doi. org/10.2989/18142320609504218

VAN STRAALEN, N. M. 2003. Ecotoxicology becomes Stress Ecology. Environ. Sci. Technol., 37: 324A-330A. http://dx.doi. org/10.1021/es0325720

VERHULST, P.F. 1845. Recherches mathématiques sur la loid'accroissement de la population. Nouv. mém. del'Academie Royale des Sci. et Belles-Lettres de Bruxelles, 18: 1-41.

VUCETICH, J. A \& PETERSON, R. O. 2012. The population biology of Isle Royale wolves and moose: an overview. http: www.isleroyalewolf.org

WANG, M. \& GRIMM, V. 2010. Population models in pesticide risk assessment: Lessons for assessing population-level effects, recovery and alternative exposure scenarios from modelling a small mammal. Environ. Toxicol. Chem., 29:1292-1300. http:// dx.doi.org/10.1002/etc. 151

ZHANG, Z., TAO, Y \& LI, Z. 2007. Factors affecting hare-lynx dynamics in the classic time series of the Hudson Bay Company, Canada. Clim. Res., 34: 83-89. http://dx.doi.org/10.3354/ cr034083 